\title{
METABOLIC STUDIES IN PARALYTIC ACUTE ANTERIOR POLIOMYELITIS. III. METABOLIC AND CIRCULATORY EFFECTS OF THE SLOWLY OSCILLATING BED ${ }^{1}$
}

\author{
By G. DONALD WHEDON ${ }^{2}$ AND EPHRAIM SHORR $\dagger$ \\ WITH THE TECHNICAL ASSISTANCE \\ of VINCENT TOSCANI AND ESTELLE STEVENS
}

\begin{abstract}
(From the Russell Sage Institute of Pathology, the Department of Medicine, Cornell University Medical College, and the New York Hospital, New York, N. Y.)
\end{abstract}

(Submitted for publication July 27, 1956; accepted November 26, 1956)

As the result of studies with normal subjects (1), the Sanders (2) oscillating bed was suggested in 1949 as a possible aid in preventing or minimizing the deteriorating effects of long immobilization. These studies showed that, during confinement to bed in casts for five weeks, healthy young men lost approximately one-half as much calcium and had less impairment in various physiological functions if placed on oscillating beds than if allowed to remain relatively motionless on ordinary hospital beds. It was pointed out that the usefulness of the Sanders bed in the management of immobilizing clinical conditions could only be determined by careful trial. The present paper reports the results of such a trial in severely paralytic acute anterior poliomyelitis.

The oscillating bed has a motorized gear device which gives it a slowly rocking head-to-foot motion. One and one-half minutes are required for the bed to tilt at a barely perceptible speed from the horizontal through 20 degrees to a head upfeet down position and to return to the original horizontal position. This bed should not be confused with the "rapid rocking bed" which rocks at rates of 16 to 30 per minute and is used in weaning poliomyelitis patients with respiratory involvement from tank respirators; nor should this bed be confused with vibrating mattresses or other devices which bring no movement to a bed. The oscillating bed's slow movement has been used for several years to increase peripheral circulation in patients with occlusive arterial disease of the extremities (3-6) and to some extent in pa-

1 Aided by a grant from the National Foundation for Infantile Paralysis.

2 Present address: National Institute of Arthritis and Metabolic Diseases, National Institutes of Health, Bethesda, Maryland.

† Died, January 6, 1956. tients with phlebothrombosis and thrombophlebitis $(7,8)$.

A study of the possible value of the slowly oscillating bed in another immobilizing clinical condition has already been made. Wyse and Pattee (9) observed the effects of oscillation in four patients with paraplegia one, two, four and thirteen months after the onset of their disease; the oscillating bed was used for eight hours a day for 12 days in three patients and for 20 days in the fourth. No change in urinary calcium was noted in three of the four patients. A gradual fall in urinary calcium (from 0.515 to $0.307 \mathrm{gm}$. per day) was noted over a twelve-day period in the patient studied two months after the onset of a transverse myelitis at D-6 and 7, but this fall was not considered significant since urinary calcium continued to decline after oscillation was stopped and remained at a low level ( 0.150 to 0.200 gm. per day) thereafter. Difficulty in collecting stools in their patients impaired interpretation of fecal calcium data and calcium balances. The oscillating bed was of value in restoring vasomotor tone of paralyzed extremities so that tendency to syncope was lessened when patients were placed in an upright position on a tilt table.

\section{PROCEDURE}

The general plan and procedure of the poliomyelitis studies were outlined in the first paper in this series (10). The present report is based on the data of eight patients. Six (M.O'M., J.C., F.S., C.R., J.W., and R.V.K.) were investigated on the Metabolism Ward where closely controlled balance studies were carried out.

The other two patients (R.Wil. and J.L.) were studied for seven and eight weeks, respectively, on the Infectious Disease Ward only. R.Wil. was a 19-year-old female student with moderately severe generalized paralysis. J.L. was a 21-year-old housewife with extreme paralysis of the shoulder girdle and upper arms. Case summaries are given in Appendix B. In these two pa- 
TABLE I

Time of institution and duration of oscillation and control intervals in eight patients with paralytic acute anterior poliomyelitis

\begin{tabular}{|c|c|c|c|c|c|c|c|c|}
\hline \multirow[b]{2}{*}{ Patient } & \multirow[b]{2}{*}{ Age } & \multirow[b]{2}{*}{ Sex } & \multirow{2}{*}{$\begin{array}{l}\text { Control } \\
\text { interval }\end{array}$} & \multicolumn{2}{|c|}{$\begin{array}{l}\text { Oscillation begun, } \\
\text { day after onset of }\end{array}$} & \multirow{2}{*}{$\begin{array}{c}\begin{array}{c}\text { Average } \\
\text { daily }\end{array} \\
\text { period of } \\
\text { oscillation }\end{array}$} & \multirow{2}{*}{$\begin{array}{l}\text { Duration } \\
\text { of oscilla- } \\
\text { tion }\end{array}$} & \multirow{2}{*}{$\begin{array}{l}\text { Post-control } \\
\text { interval } \\
\text { reported }\end{array}$} \\
\hline & & & & Illness & Paralysis & & & \\
\hline \multicolumn{9}{|c|}{$\begin{array}{l}\text { days } \\
\text { Acute and early convalescent phase }\end{array}$} \\
\hline $\begin{array}{l}\text { M. O'M. } \\
\text { J. C. } \\
\text { R. Wil. } \\
\text { J. L. }\end{array}$ & $\begin{array}{l}21 \\
39 \\
19 \\
21\end{array}$ & $\begin{array}{l}F \\
M \\
F \\
F\end{array}$ & $\begin{array}{r}4 \\
8 \\
3 \\
12\end{array}$ & $\begin{array}{r}8 \text { th } \\
14 \text { th } \\
7 \text { th } \\
24 \text { th }\end{array}$ & $\begin{array}{r}5 \text { th } \\
12 \text { th } \\
6 \text { th } \\
24 \text { th }\end{array}$ & $\begin{array}{l}14 \\
17 \\
10 \\
16\end{array}$ & $\begin{array}{l}33 \\
26 \\
17 \\
21\end{array}$ & $\begin{array}{l}30 \\
30 \\
28 \\
15\end{array}$ \\
\hline \multicolumn{9}{|c|}{ Convalescent phase } \\
\hline C. R. & $\begin{array}{l}20 \\
18\end{array}$ & $\begin{array}{l}M \\
M\end{array}$ & $\begin{array}{l}18 \\
24^{*} \\
24\end{array}$ & $\begin{array}{l}53 \text { rd } \\
107 \text { th } \\
80 \text { th } \\
128 \text { th }\end{array}$ & $\begin{array}{r}50 \text { th } \\
104 \text { th }\end{array}$ & $\begin{array}{c}21 \\
21 \\
t \\
+ \\
+\end{array}$ & $\begin{array}{r}30 \\
18 \\
30 \\
114\end{array}$ & $\begin{array}{c}24^{*} \\
30 \\
18 \\
8\end{array}$ \\
\hline \multicolumn{9}{|c|}{ Chronic phase } \\
\hline $\begin{array}{l}\text { J. W. } \\
\text { R. V. K. }\end{array}$ & $\begin{array}{l}20 \\
19\end{array}$ & $\begin{array}{l}\mathrm{F} \\
\mathrm{F}\end{array}$ & $\begin{array}{l}42 \\
36\end{array}$ & $\begin{array}{l}258 \text { th } \\
542 \text { nd }\end{array}$ & & $\begin{array}{l}18 \\
18\end{array}$ & $\begin{array}{l}42 \\
42\end{array}$ & $\begin{array}{l}21 \\
30\end{array}$ \\
\hline
\end{tabular}

* Twenty-four-day interval between two intervals of oscillation.

† Sanders slow oscillation 14 hours daily, rapid rocking 7 to 8 hours daily.

$\ddagger$ Rapid rocking only, 10 to 12 hours daily.

$\S$ No post-control interval; patient began sitting in chair when rapid rocking was stopped.

tients daily 24-hour urine collections were made; stools were not collected. Their dietary intake was calculated but not weighed or kept rigidly constant since metabolic kitchen facilities were not available. The data of these two patients, therefore, are of less value than those of the other six patients. Dietary intakes of patients previously reported were given in Table I of the first paper (10). Dietary intakes of R.Wil. and J.L. as calculated from survey of food served and returned are given in Tables II and III of the present report.

Four patients were studied during the acute and early convalescent phases of poliomyelitis, two during the convalescent phase and two during the chronic phase. Duration of oscillation, time of its institution, length of control intervals before and after oscillation and other details of experimental procedure are given in Table I. Con-

TABLE II

Patient, R. Wil.-Average daily dietary calories, nitrogen and calcium; and urinary creatinine, nitrogen and calcium during acute and early convalescent phases of paralytic acute anterior poliomyelitis *

\begin{tabular}{|c|c|c|c|c|c|c|c|}
\hline \multirow{2}{*}{$\begin{array}{l}\text { Day } \\
\text { after } \\
\text { onset }\end{array}$} & \multicolumn{3}{|c|}{ Dietary } & \multicolumn{3}{|c|}{ Urinary } & \multirow{2}{*}{$\begin{array}{l}\text { Phase } \\
\text { of } \\
\text { study }\end{array}$} \\
\hline & Calories & $\mathrm{N}$ & $\mathrm{Ca}$ & Creatinine & $\mathbf{N}$ & $\mathrm{Ca}$ & \\
\hline $4-6$ & 1,142 & $\begin{array}{l}g m . \\
12.4\end{array}$ & $g m$. & $\begin{array}{c}g m . \\
0.950\end{array}$ & $\begin{array}{l}g m . \\
15.01\end{array}$ & $\begin{array}{c}g m . \\
0.132\end{array}$ & Control \\
\hline $\begin{array}{c}7,8 \\
10,12 \\
13-15 \\
17-19 \\
20-23\end{array}$ & $\begin{array}{r}1,055 \\
756 \\
938 \\
950 \\
1,080\end{array}$ & $\begin{array}{r}12.2 \\
8.2 \\
10.0 \\
10.0 \\
11.5\end{array}$ & $\begin{array}{l}0.661 \\
0.528 \\
0.810 \\
0.925 \\
0.925\end{array}$ & $\begin{array}{l}1.042 \\
1.007 \\
1.037 \\
0.985 \\
0.863\end{array}$ & $\begin{array}{l}16.80 \\
18.81 \\
17.72 \\
13.08 \\
13.59\end{array}$ & $\begin{array}{l}0.206 \\
0.223 \\
0.221 \\
0.192 \\
0.211\end{array}$ & $\begin{array}{c}\text { Oscillating } \\
\text { bed }\end{array}$ \\
\hline $\begin{array}{l}24,25 \\
26,27 \\
28-31 \\
32-34 \\
35-37 \\
39-41 \\
42,43 \\
44-46 \\
47-49 \\
50,51\end{array}$ & $\begin{array}{r}1,085 \\
1,176 \\
1,110 \\
1,185 \\
1,051 \\
1,124 \\
1,106 \\
1,085 \\
953\end{array}$ & $\begin{array}{r}10.8 \\
11.6 \\
11.4 \\
12.3 \\
11.2 \\
11.9 \\
11.7 \\
11.2 \\
9.3\end{array}$ & $\begin{array}{l}0.912 \\
0.912 \\
0.908 \\
0.958 \\
0.940 \\
0.941 \\
0.900 \\
0.951 \\
0.892 \\
0.883\end{array}$ & $\begin{array}{l}0.860 \\
0.875 \\
0.925 \\
0.900 \\
0.897 \\
0.850 \\
0.775 \\
0.820 \\
0.760 \\
0.760\end{array}$ & $\begin{array}{l}12.29 \\
13.39 \\
14.03 \\
14.00 \\
13.80 \\
14.52 \\
12.38 \\
12.99 \\
11.98 \\
10.92\end{array}$ & $\begin{array}{l}0.159 \\
0.157 \\
0.244 \\
0.218 \\
0.283 \\
0.274 \\
0.240 \\
0.238 \\
0.237 \\
0.265\end{array}$ & Control \\
\hline
\end{tabular}

* Onset of illness, October 12, 1949 ; paralysis October 13. 
trol intervals prior to oscillation were brief in the studies during acute and early convalescent phases but were from four to six metabolic balance periods ( 24 to 36 days) in duration in the observations during later phases.

When oscillation was begun, the bed was rocked for as many hours as possible of the 24 , being stopped only for muscle re-education, meals, bed baths and use of the bedpan. Sleep was possible during oscillation and in some instances seemed to be aided by the motion. The daily period of oscillation averaged 19 hours for the patients studied during the convalescent and chronic phases, but was necessarily limited to 10 to 18 hours during the early weeks in two patients (M.O'M. and R.Wil.) because constant motion increased muscular discomfort, mainly around the shoulders. The bed mechanism was set to rock through the maximum arc, $18^{\circ}$ to $21^{\circ}$, from horizontal (or $2^{\circ}$ head-down) to extreme foot-down position and return in one and one-half minutes. The patient's feet were placed against a foot-board so that pressure was felt on soles and heels in the foot-down position.

One patient, C.R., was placed on a rapid rocking bed during part of his study to observe the influence of rapid rocking not on metabolism but on impaired ventilatory capacity. For a thirty-day period during the third and fourth months after onset of illness, he was placed on a rapid rocking bed for 7 to 8 hours a day (rate $16 / \mathrm{min}$., total arc $24^{\circ}$, or $12^{\circ}$ each side of horizontal) and on a Sanders bed for 14 hours daily. Later he remained on a rapid rocking bed for 10 to 12 hours a day for four months while other experimental procedures were carried out.

\section{METHODS}

Methods for analysis of urine, stool and serum for calcium, phosphorus, nitrogen, creatine, creatinine, sodium and potassium have been previously stated $(10,11)$. Methods of studying reaction of the circulation in motionless standing by tilt table test and of measuring girth of thighs and calves have also been previously described $(10,11)$. Coagulation time was determined by a modification (11) of the Lee and White method for venous blood and prothrombin time by the Link-Shapiro method (12).

Skin temperatures were measured periodically in four patients using the Hardy radiometer (13) which is more accurate and sensitive $\left( \pm 0.01^{\circ} \mathrm{C}\right)$ than other devices and avoids errors inherent in the use of thermocouples placed directly on the skin (14). Readings were taken in 20 individual areas over the body surface; for calculation of the average skin temperature over the total surface of the body, readings were weighted by the formula of Hardy and DuBois (15). In two patients determinations of total peripheral blood flow to the skin were carried out by the method of Hardy and Soderstrom (16), as given in detail by Stewart and Evans (17) except that Hardy's original 20 areas of the skin were used. In addition to measurements of skin temperature with the radiometer, the total peripheral blood flow method makes use of measurements of rectal temperature with a single junction copper-constantan thermocouple $\left( \pm 0.02^{\circ} \mathrm{C}\right)(13)$ and of oxygen consumption with a Benedict-Roth metabolism apparatus (18). All determinations of skin temperature and peripheral blood flow were made in the basal metabolic state in a controlled temperature room; for each determination at least two sets of skin temperature readings were made at intervals of 20 minutes.

\section{RESULTS}

\section{A. Metabolic Constituents}

1. Calcium excretion and balance. In the four patients studied during the acute and early convalescent phases, urinary calcium was increasing gradually during the brief control interval prior to oscillation. When oscillation was begun, a variety of responses took place. In one patient, J.C., urinary calcium continued to rise for another six to nine days when a level averaging $0.534 \mathrm{gm}$. per day was reached, then maintained for several weeks (Figure 1). In M.O'M., coincident with beginning of oscillation, urinary calcium remained at a level of $0.254 \mathrm{gm}$. per day for two weeks; then, while the patient was still on the oscillating bed, urinary calcium rose to a new level of $0.370 \mathrm{gm}$. per day (Figure 1). R.Wil.'s urinary calcium remained quite constant during oscillation at $0.210 \mathrm{gm}$. per day (Figure 2). In the fourth patient, J.L., who with R.Wil. was not on the Metabolism Ward, urinary calcium declined from an average level of $0.394 \mathrm{gm}$. per day at the time oscillation was instituted to $0.313 \mathrm{gm}$. In the two patients on whom balance studies had been begun, J.C. and M.O'M., calcium balances were -0.385 and $-0.295 \mathrm{gm}$. per day, respectively, during oscillation on a constant calcium intake of $0.920 \mathrm{gm}$. per day (Figure 1).

Since it was difficult to compare the changing levels of excretion of the brief initial control phases with those during oscillation and also since dietary calcium intakes were varying until after oscillation had been started, particular attention was focused on whether calcium excretion would rise when oscillation was discontinued. When that was done, three of the four patients showed no change in urinary calcium excretion; in the two on complete balance studies, no significant change occurred in negative calcium balance. In the fourth patient, R.Wil., mean daily urinary calcium excretion increased from $0.210 \mathrm{gm}$. per day to an average of 
TABLE III

Patient, J. L.-Average daily dietary calories, nitrogen and calcium; and urinary creatinine, nitrogen and calcium during early convalescent phase of paralytic acute anterior poliomyelitis*

\begin{tabular}{|c|c|c|c|c|c|c|c|}
\hline \multirow{2}{*}{$\begin{array}{l}\text { Day } \\
\text { after } \\
\text { onset }\end{array}$} & \multicolumn{3}{|c|}{ Dietary } & \multicolumn{3}{|c|}{ Urinary } & \multirow{2}{*}{$\begin{array}{l}\text { Phase } \\
\text { of } \\
\text { study }\end{array}$} \\
\hline & Calories & $\mathbf{N}$ & $\mathrm{Ca}$ & Creatinine & $\mathbf{N}$ & $\mathrm{Ca}$ & \\
\hline • & & $\mathrm{gm}$ & $g m$. & $g m$ & $g m$. & $g m$ & \multirow{5}{*}{ Control } \\
\hline $12-14$ & 1,182 & 6.7 & 0.315 & 0.800 & 12.32 & 0.270 & \\
\hline $15-17$ & 1,787 & 9.8 & 0.648 & 0.897 & 13.82 & 0.296 & \\
\hline $18-20$ & 1,895 & 9.6 & 0.465 & 0.856 & 12.68 & 0.362 & \\
\hline $21-23$ & 1,705 & 9.2 & 0.485 & 0.747 & 9.68 & 0.381 & \\
\hline $24-26$ & 1,732 & 9.0 & 0.365 & 0.803 & 12.76 & 0.407 & \multirow{7}{*}{$\begin{array}{c}\text { Oscillating } \\
\text { bed }\end{array}$} \\
\hline $27-29$ & 2,000 & 9.1 & 0.602 & 0.750 & 11.70 & 0.315 & \\
\hline 31,32 & 1,970 & 7.8 & 0.359 & 0.720 & 9.33 & 0.332 & \\
\hline $33-35$ & 2,293 & 10.1 & 0.643 & 0.720 & 10.25 & 0.316 & \\
\hline $36-38$ & 1,741 & 10.7 & 0.595 & 0.817 & 12.67 & 0.285 & \\
\hline $39-41$ & 2,068 & 8.2 & 0.927 & 0.690 & 9.75 & 0.309 & \\
\hline $42-44$ & 2,106 & 8.8 & 0.805 & 0.707 & 11.37 & 0.319 & \\
\hline $45-47$ & 2,413 & 10.9 & 1.119 & 0.640 & 10.13 & 0.302 & \multirow[t]{5}{*}{ Control } \\
\hline $48-50$ & 2,118 & 11.7 & 0.892 & 0.656 & 10.01 & 0.308 & \\
\hline $51-53$ & 2,258 & 10.4 & 0.997 & 0.750 & 10.72 & 0.330 & \\
\hline 54-56 & 1,944 & 11.2 & 0.812 & 0.677 & 9.96 & 0.284 & \\
\hline $57-59$ & 1,865 & 11.0 & 0.834 & 0.690 & 11.61 & 0.329 & \\
\hline
\end{tabular}

* Onset of illness and paralysis, October 1, 1948.

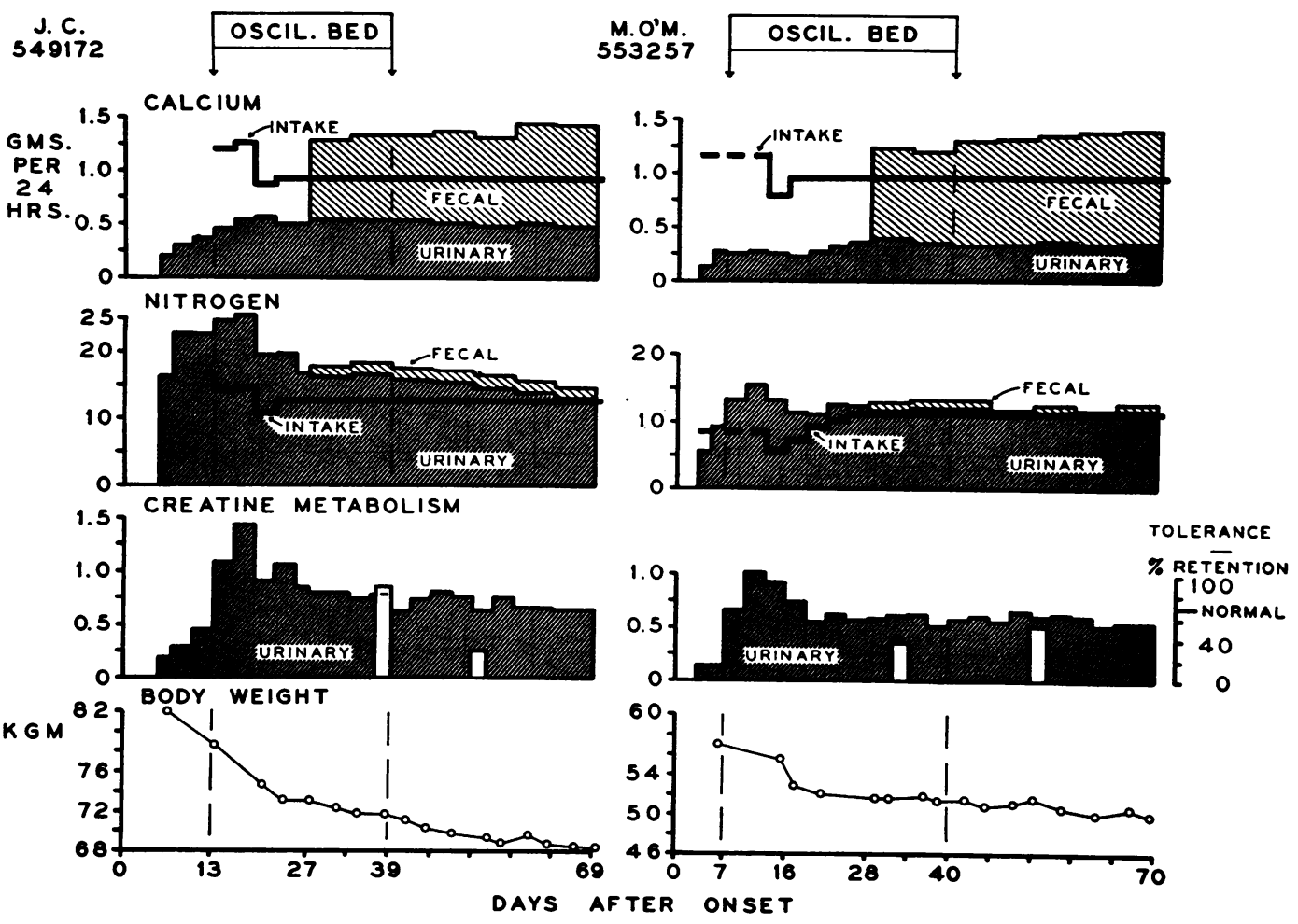

Fig. 1. Calcium and Nitrogen Balance, Urinary Creatine, Creatine Tolerance and Body Weight - Prior to, During and Following Oscillation in the Acute and Early Convalescent Phase, Patients J.C., 39-Year-Old Male and M.O'M., 21-Year-Old Female

Calcium and nitrogen data are charted with intake and output both plotted upward from the base-line and urinary output on the bottom in order to portray clearly changes in urinary excretion of these elements as well as changes in balance. 


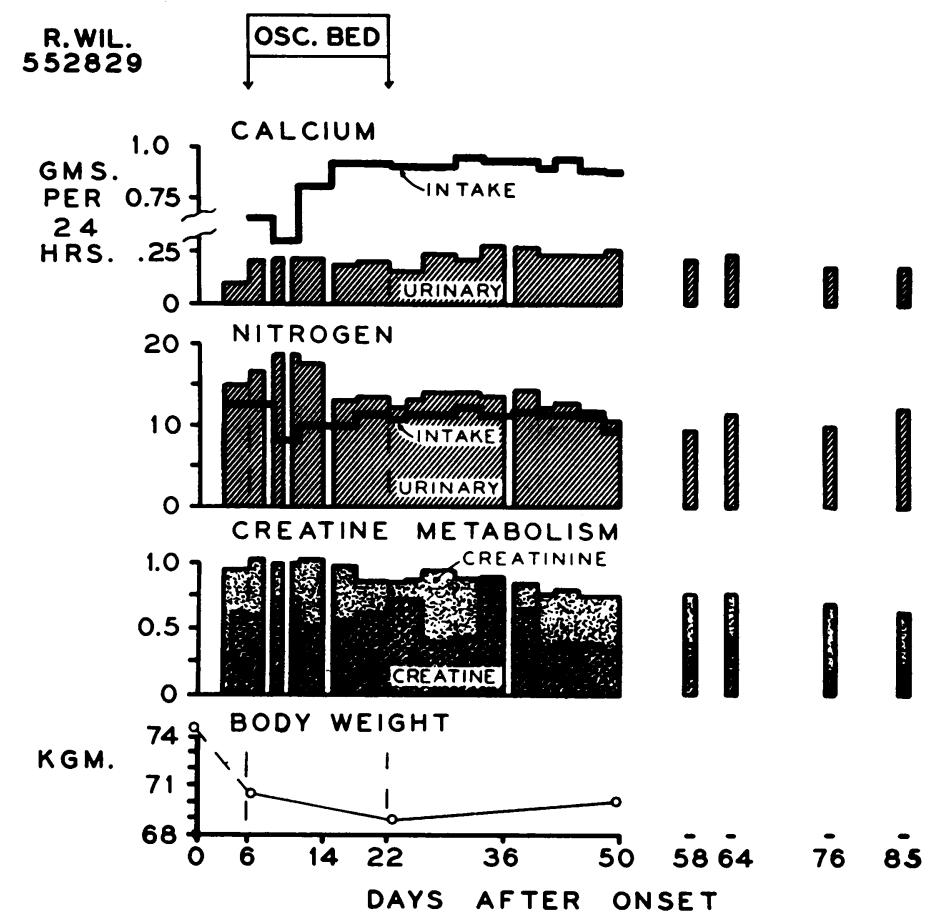

Fig. 2. Urinary Calcium, Nitrogen, Creatine and Creatinine and Body Weight Prior to, During and Following Oscillation in the Acute and Early Convalescent Phase, Patient R.Wil., 19-Year-Old Female

Urinary creatine and creatinine are plotted together, creatinine in stippled tone overlapped by creatine in cross-hatched tone.

0.250 during the 28 days immediately following oscillation.

Two patients, F.S. and C.R., were placed on oscillating beds during the third and fourth months after onset. In F.S. (Figure 3), a very gradual downward trend in the level of urinary calcium and decreasing negativity of calcium balance were unaffected by a 30 -day and an 18-day phase of oscillation. In C.R., a high level of urinary calcium excretion and of negative calcium balance was unchanged by oscillation.

During the chronic phase of the disease, calcium excretion and balance of J.W. showed no change as the result of oscillation. While R.V.K. (Figure 4) was on an oscillating bed, there was reduction in calcium excretion, mainly in the fecal component, and development of a positive calcium balance $(+0.209 \mathrm{gm}$. per day $)$. This change probably should not be attributed to oscillation, however, since calcium excretion did not revert to its original level after oscillation was discontinued.

2. Nitrogen excretion and balance. The only suggestive influence of oscillation on nitrogen metabolism occurred in F.S. during the convalescent phase (Figure 3 ) when urinary nitrogen excretion and negative nitrogen balance were gradually diminishing. Oscillation did not appear to alter this gradual decline, but when oscillation was stopped nitrogen excretion increased by approximately 1 gm. daily, suggesting the possibility that oscillation had decreased nitrogen excretion from what it would otherwise have been. To check this possibility, F.S. was placed on an oscillating bed for a second time; during this second observation average nitrogen excretion was not significantly decreased, and no after-rise took place when oscillation was discontinued. The reason for the change in nitrogen excretion following the first phase of oscillation is obscure. No changes in 


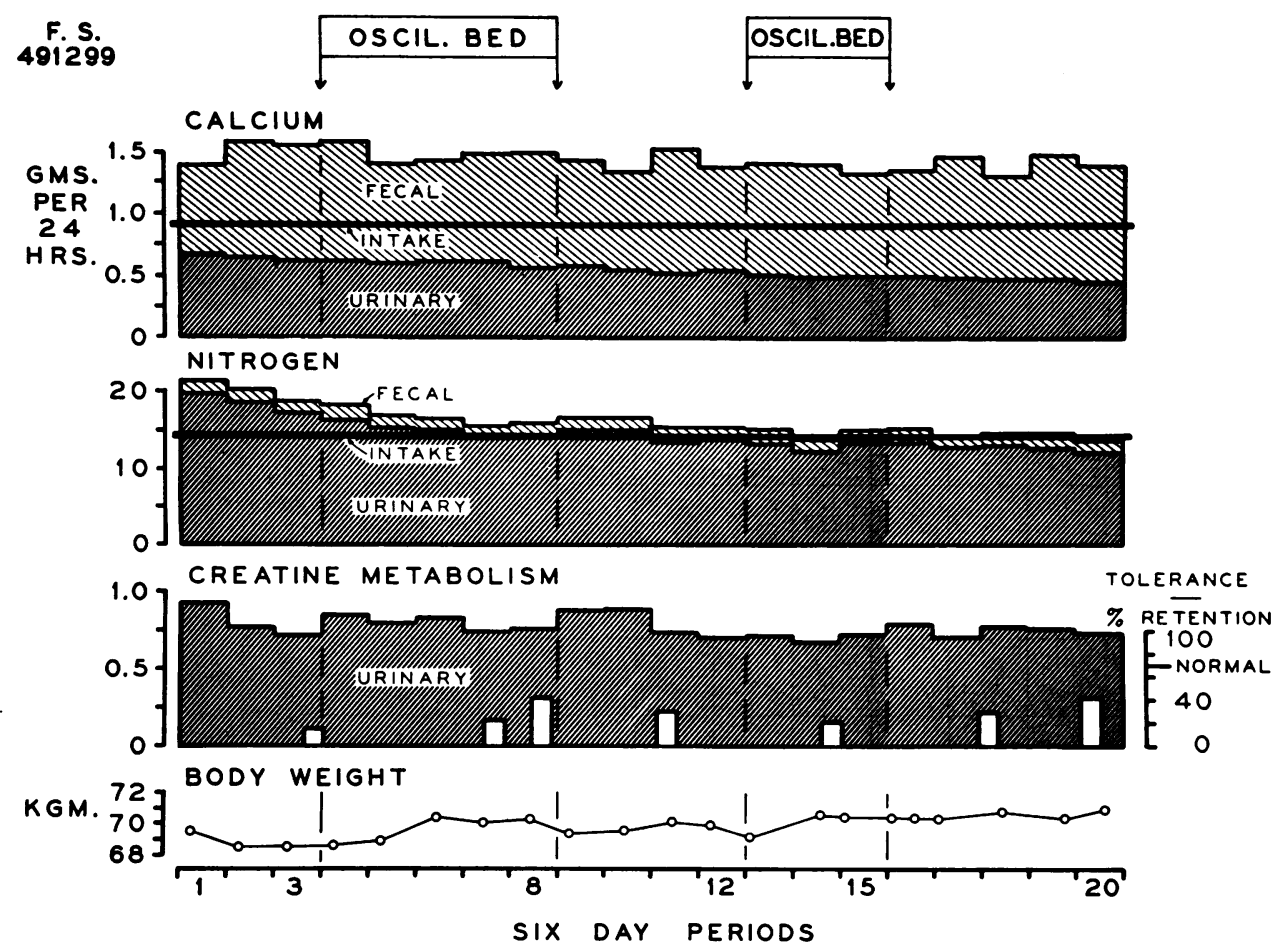

Fig. 3. Calcium and Nitrogen Balance, Urinary Creatine, Creatine Tolerance and Body Weight Prior to, During and Following a 30-Day and an 18-Day Period of Oscillation in the Convalescent Phase, Patient F.S., 20-Year-Old Male

Explanation of construction of balance chart for calcium and nitrogen in legend for Figure 1.

nitrogen excretion attributable to oscillation occurred in any of the other patients.

Although in J.C. and M.O'M. urinary nitrogen was at its highest level during their first twelve days on the bed, this finding was thought not attributable to oscillation since the same pattern of nitrogen excretion was seen during the same period after onset of illness in two other patients, D.Q. and D.A., who were not placed on oscillating beds.

3. Other metabolic constituents. In one patient, M.O'M., urinary citric acid increased with the rise in urinary calcium during the period she was on an oscillating bed. Since, however, this patient's citric acid excretion remained high after oscillation was discontinued, the elevation in citric acid was thought not to be an effect of oscillation.

In various patients minor changes occurred in urinary creatine excretion, creatine tolerance and in sodium balance which had no clear or consistent relationship to oscillation. No influence of oscillation was noted in phosphorus and potassium ex- cretion and balance, in urinary creatinine and in serum calcium, phosphorus and alkaline phosphatase.

The urinary calcium and nitrogen data of patients R.Wil. and J.L. are given in Tables II and III. Data of patients J.C., M.O'M., F.S., C.R., J.W. and R.V.K. are given in tables in Appen$\operatorname{dix}$ A.

\section{B. Physiological Measurements}

1. Circulatory reactions to gravity as measured by tilt table tests. During initial periods of study when the patients were largely confined to bed, regardless of phase of poliomyelitis, all patients exhibited impairment in the ability to maintain adequate circulation in the upright position. This impairment was indicated by the development of dizziness, pallor, darkening of vision, and slight nausea within thirty minutes of the time patients were elevated to an angle of 40 to 50 degrees from the horizontal on a tilt table. Impairment was more marked during the early convalescent phase 


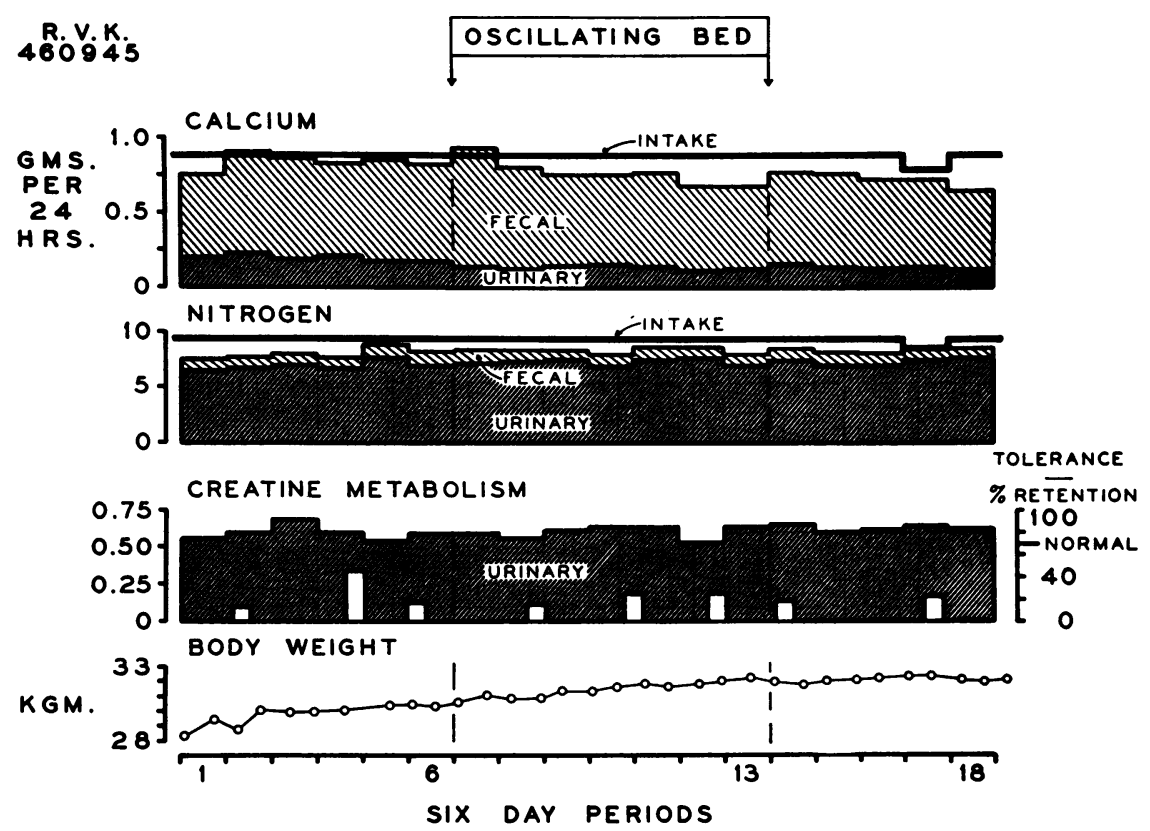

Fig. 4. Calcium and Nitrogen Balance, Urinary Creatine, Creatine Tolerance and Body Weight Prior to, During and Following Oscillation in the Chronic Phase, Patient R.V.K., 19-Year-Old Female

Explanation of construction of balance chart for calcium and nitrogen in legend for Figure 1.

of the disease, symptoms appearing in less than twenty minutes when patients were tested on the tilt table during this phase.

A series of tests were performed at intervals before, during and following the periods of study on the oscillating bed, on patients F.S. and C.R. during the convalescent phase and on J.W. and R.V.K. during the chronic phase. These tests showed that during the oscillation phase patients could tolerate a longer period in the upright tilted position before symptoms heralding fainting began to occur. Figure 5 indicates the effect of oscillation on tilt table tests in these patients, showing the number of minutes required for the pulse pressure to fall to a level of 10 to $12 \mathrm{~mm}$. of mercury when the subjects were tilted upright on the tilt table. This pulse pressure level was selected as the end-point for comparison of various tilt table tests as a result of analysis of tests performed during the immobilization study of normal subjects. Correlation of data on blood pressure and pulse rate with symptomatic reactions had indicated that pulse pressure was the most important factor involved in the response of the circulation to tilting.
With a subject in the upright position on the tilt table, it was found that when the pulse pressure became reduced to between 10 and $12 \mathrm{~mm}$. of mercury a critical level was reached at which circulation became impaired, dizziness and pallor appeared and fainting followed shortly thereafter. The next most important factor was the fall in systolic pressure. Similarly, Graybiel and McFarland (19), in an analysis of tilt table tests on ninety-one normal individuals, concluded that pulse pressure and fall in systolic pressure were the most important factors indicating a failing circulation.

2. Skin temperature and peripheral blood flow. A number of studies of skin temperature and peripheral blood flow were carried out on the two patients observed during the chronic phase of the disease, seven on J.W. and three on R.V.K. ; both patients had marked paralysis of the leg muscles and clinically "cold" lower extremities.

Oscillation over a period of six weeks brought about no increase in the average skin temperature of the whole body (measured in 20 areas), but significantly raised the skin temperature of the 


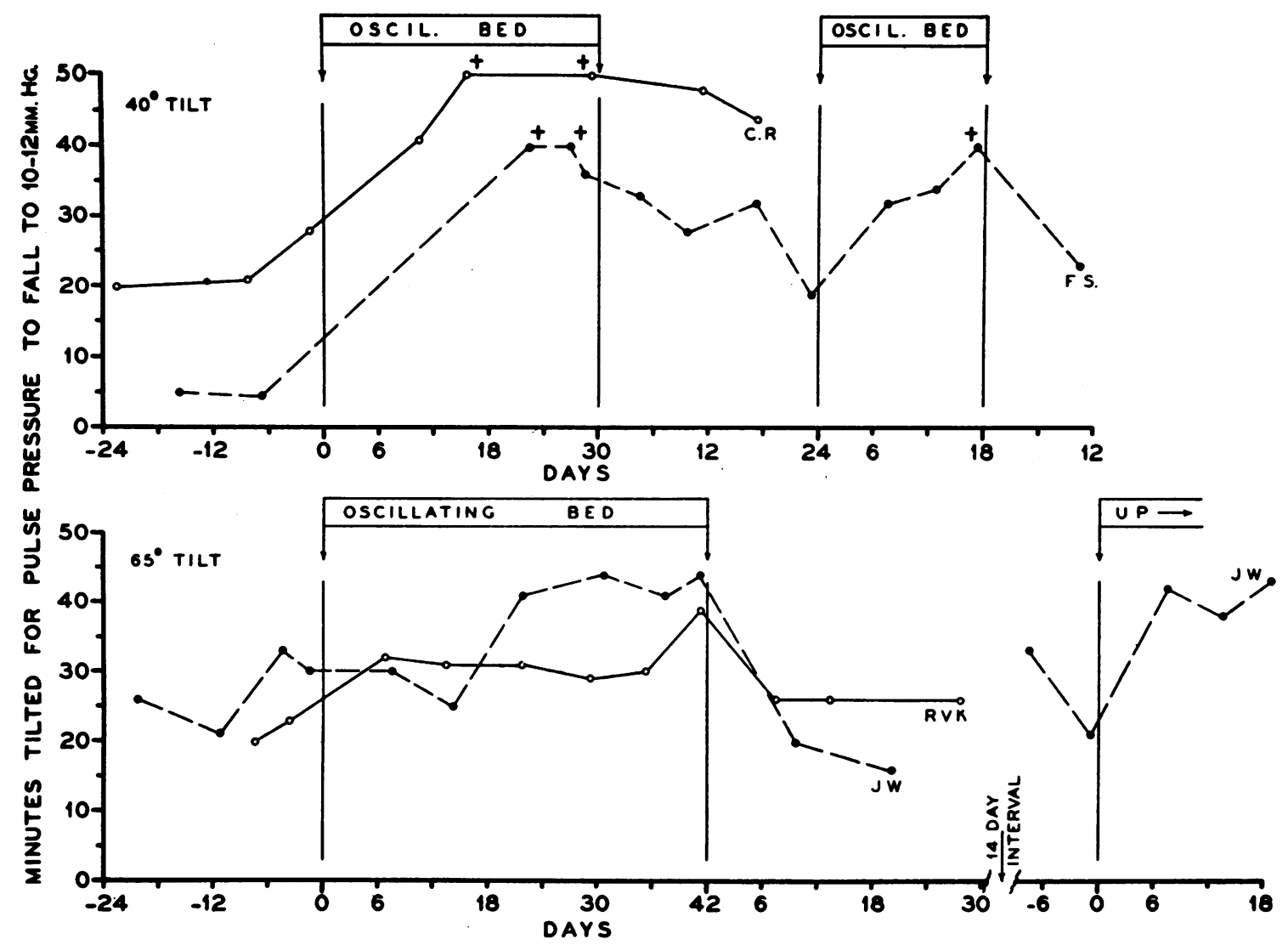

Fig. 5. Effect of Oscillation on the Results of Tilt Table Tests in Four Patients During the Convalescent (Upper Part of Graph) and Chronic (Lower) Phases, Showing the Number of Minutes in the Tilted Position for the Pulse Pressure to Fall to Critical Levels of 10 to 12 mm. of Hg

Plus sign beside test result indicates patient was able to remain in the tilted position for longer than the time shown without developing critical level of pulse pressure.

feet. In J.W. prior to oscillation, feet skin temperatures (average of two areas) were 34.0 and 33.9 degrees $\mathrm{C}$ in measurements on two occasions. On the first study during oscillation no appreciable change was noted, but readings in the next three studies were $35.6,35.8$ and 35.45 degrees $C$ (bed stationary during tests). Two weeks after oscillation was discontinued the reading was 35.0 degrees C. Room temperatures in the climatically controlled room during the tests were within \pm 0.5 of 30.0 degrees $C$, averaging 30.0 before, 30.2 during, and 30.0 after oscillation. In R.V.K., feet skin temperature was 30.0 degrees $\mathrm{C}$ at a room temperature of 29.3 in a single determination (two sets of readings) before oscillation was begun. During the oscillation phase feet skin temperature rose to 33.8 and 33.9 degrees $\mathrm{C}$; room temperatures were 29.3 and 30.2 degres $C$, re- spectively. Leg temperatures (four areas) of R.V.K. increased from 33.0 to 34.5 and 34.0 degrees $\mathrm{C}$, but in J.W. the mean leg temperature increase was only 0.4 degrees C. Measurements of feet skin temperature in both patients first with the oscillating bed stationary and then while the bed was oscillating revealed no acute warming effect as measured either within a few minutes after the bed was started or after the bed had been oscillating for 40 to 90 minutes.

Peripheral blood flow determinations yielded results which were not clear inasmuch as there seemed to be an acute effect of oscillation in one patient and a chronic effect in the other. Two determinations in J.W. before oscillation were 158 and $184 \mathrm{ml}$. per M. ${ }^{2}$ per min., mean 171 ; during oscillation successive values were $165,177,173$ and $176 \mathrm{ml}$. per M. ${ }^{2}$ per min. (bed stationary dur- 
ing tests) with a value of 166 two weeks after. With the bed oscillating for 90 minutes, values of 199, 214, 165 and 231 were obtained, a mean increase of $30 \mathrm{ml}$. per M. ${ }^{2}$ per min. or 17 per cent. In R.V.K. the peripheral blood flow was $114 \mathrm{ml}$. per M. ${ }^{2}$ per min. before oscillation and 144 on each of two tests during; with the bed oscillating, blood flow further increased to 151 and 153, an additional 5.5 per cent rise.

In two patients, F.S. and C.R., studied during the convalescent phase a series of seven and five tests, respectively, of skin temperature were carried out. With oscillation, changes in total average skin temperature and temperature of legs and feet were all less than 0.7 degrees C. Peripheral blood flow was not determined in these patients.

3. Leg girth. No consistent effect on leg girth was brought about by oscillation. In three patients, C.R., R.V.K., and F.S. during his first study on the oscillating bed, an increase was noted in circumference of the calves of 1.0 to $1.3 \mathrm{~cm}$. This increase was thought to be due mainly to accumulation of extracellular fluid in the legs from sustained increased hydrostatic pressure resulting from the fact that the bed was adjusted to rock back just to the horizontal from the foot-down position. This retention of fluid in leg tissues was manifested by slight puffiness about the ankles in F.S. and must partially account for the weight gain during oscillation in this patient (Figure 3 ). In patients for whom the bed was adjusted to rock back to approximately 2 degrees head down, permitting leg veins to empty fully, increase in leg girth was either slight or did not occur; in F.S.'s second time on the bed with the bed so adjusted, for example, increase in leg girth was minimal.

4. Ventilation. One patient in the chronic phase of poliomyelitis, R.V.K., had a markedly limited vital capacity, $505 \mathrm{ml}$. During six weeks of oscillation her vital capacity increased gradually to $640 \mathrm{ml}$.

F.S., placed on an oscillating bed two months after onset, showed an increase in vital capacity with oscillation from $3400 \mathrm{ml}$. to $3680 \mathrm{ml}$. and an increase in maximum minute ventilation capacity from 60 to 74 liters; during control periods after oscillation these values did not increase further. C.R., also in the convalescent phase, because of limited ventilatory capacity was placed on a rapid rocking bed as well as on a Sanders bed. In- creases in vital capacity, tidal air and maximum minute ventilation capacity in this patient were presumably mainly attributable to rapid rocking, the effects of which we have reported elsewhere (20).

5. Other physiological tests. Periodic ergometer tests of gastrocnemius-soleus muscle power in two convalescent patients, F.S. and C.R., indicated no alteration in the rate of recovery of muscle strength as the result of oscillation. Basal metabolism was measured approximately every two weeks in six patients (in two patients during each disease phase), and no influence of oscillation was noted; tests while the bed oscillated showed the cyclic shift in diaphragm mid-position level previously mentioned (1) but no significant increase in oxygen consumption. Clotting and prothrombin times remained normal in the three patients (F.S., C.R. and R.V.K.) in whom this function was measured.

\section{COMMENT}

These studies of effects of the Sanders oscillating bed in patients with paralytic poliomyelitis indicated modest physiological changes from its use. These changes were not of the kind or magnitude, however, which would lead to recommendation of the bed for management of patients immobilized by poliomyelitis.

\section{Changes in calcium excretion}

The metabolic function under particular scrutiny was calcium excretion and balance. Since losses of calcium in paralytic poliomyelitis are sufficient to lead to osteoporosis and possibly to urinary tract stone formation (21), a means of diminishing these losses would be of considerable value. During acute and early convalescent phases, when demonstration of a restraining action on calcium excretion would have been particularly meaningful, preliminary control periods were necessarily brief and calcium intake variable so that comparison of initial levels of calcium excretion with levels during the oscillation periods was difficult to interpret. Positive effect of oscillation, therefore, would be indicated only by a significant rise in calcium excretion after oscillation had been stopped. In only one of the four patients studied during this early phase was the mean urinary calcium excretion after oscillation statistically different from 
the mean level during oscillation; the difference between these means in R.Wil. was 3.5 times the S.E. of the difference between the means (22). However, although this difference was statistically significant, a change of much greater magnitude would be necessary for one to consider that oscillation had prevented calcium loss to a biologically significant degree. Furthermore, even if oscillation had been shown to minimize calcium losses during the early phases, muscle spasm, tenderness and discomfort during the early weeks were in a number of patients accentuated by oscillation, suggesting impracticality. Studies during the later convalescent and chronic phases indicated no appreciable reductive action of oscillation on calcium loss. These largely negative findings with respect to the effect of oscillation on calcium metabolism are in general agreement with the previously mentioned results of Wyse and Pattee in four paraplegics (9).

\section{Possible factors in lack of effect on calcium excretion}

A number of reasons may be suggested for the ineffectiveness of the oscillating bed in preventing calcium loss in paralytic poliomyelitis as compared with its benefit in immobilized normal subjects. In the latter investigation oscillation was begun as soon as the subjects were placed in casts. Although in the poliomyelitis patients observed during the acute phase the duration of paralysis prior to oscillation was only a few days (mean for first three patients, 8 days), it is conceivable that a trend toward calcium loss may have already become so well established that the oscillating bed could not appreciably reverse the process. A second difference between the two studies is that, despite the fact that the normal subjects were in casts from waist to toes, the degree of immobilization of the poliomyelitis patients was greater. Furthermore, neurological injury per se may have had some influence on calcium balance, although evidence has been previously cited (21) that this was probably not a major factor and that immobilization seemed principally responsible for calcium loss in these patients.

Mechanical factors may also have been partly responsible for differences in the two series. Muscle paralysis in the poliomyelitis patients either greatly reduced or prevented muscle pull on periosteal surfaces of the leg bones; in the normal group such a pull was thought to occur to a considerable degree as the bed shifted its position back and forth. Since this form of "stress and strain" was largely absent in the poliomyelitis patients, stimulation of bone formation was limited to the slight, intermittent weight-bearing occurring in the foot-down position of the bed. This was far less than full weight-bearing, an apparently potent stimulus to mineral storage even in the absence of leg muscle function, as demonstrated by the Abramson study (23) of ambulatory paraplegics, a different type of paralysis from poliomyelitis.

Another possible mode of action of oscillation postulated to explain the favorable result in the experiment with normal subjects (1) was an increase in peripheral and, presumably, bone circulation. As mentioned in the preceding paper, however, there is no agreement that bone formation is favored by increased circulation. Further, although in both studies the bed's motion was identical and improved circulation to the legs and feet was indicated, the definite effect on calcium excretion observed in the normal group was not seen in the poliomyelitis study. With this evidence, it may be questioned whether circulatory effects of the oscillating bed had any relationship to the favorable effects with respect to calcium in the normal subjects.

\section{Reaction of circulation to gravity}

Among the various physiological functions, the mechanisms responsible for circulatory control in the upright position have been the most consistently influenced by oscillation. In immobilized normal subjects circulatory reflexes as measured by tilt table tests were maintained almost at control levels by oscillation and their deterioration from immobilization on a fixed bed largely prevented (1). Wyse and Pattee (9) reported the bed to be of value in restoring vasomotor tone of the extremities in their paraplegic patients. In the present study when patients were being oscillated, they could tolerate a much longer period of time in the upright position on the tilt table.

The degree of impairment of these circulatory reflexes in paralytic poliomyelitis appeared to be 
similar to that resulting from immobilization alone. The altered tilt table test response of pulse and blood pressure among the five patients tested (before and after oscillation) was of approximately the same magnitude as was noted in the normal subjects immobilized on a fixed bed for six to seven weeks (11). Analysis of the measurements of the circumference of the legs made every two to three minutes during and after tilting in tests during the study with normal subjects had suggested that during immobilization there was impairment of either venous or muscular tone or both. Similar measurements in two poliomyelitis patients studied during the chronic phase revealed no differences in the changes in these measurements from those in the normal subjects. No evidence was elicited in the patients to indicate that muscle paralysis due to poliomyelitis resulted in poorer support of blood vessels than would occur from immobilization alone. The possibility of a circulatory effect of paralysis of this sort cannot be excluded, however, in view of the small number of tests made with these measurements.

\section{Peripheral circulatory effects of oscillation}

Beneficial results observed in vascular diseases of the lower extremities with use of the oscillating bed have been attributed to improvement in blood flow brought about by the motion of the bed. Conclusive evidence for this action has not been presented although some measurements of peripheral circulation have been made $(6,24)$. In the study of normal subjects (1) change in venous pressure in the dorsal footveins of $140 \mathrm{~mm}$. of water with each cycle of the bed was interpreted to indicate that in the presence of competent venous valves a larger volume of blood was being delivered to the right auricle during oscillation; skin temperatures were not measured. In the present study, although no immediate warming effect of skin temperatures of the feet and legs by oscillation was demonstrated, over the course of three weeks a distinct increase in feet skin temperature was noted in the two patients studied during the chronic phase. An increase of more than $1^{\circ} \mathrm{C}$ measured with the Hardy radiometer can be considered highly significant, particularly under the environmental conditions used for these measurements. The high room temperature $\left(30^{\circ} \mathrm{C}\right)$ fa- vored near-maximal vasodilatation, and the fact that these tests were done during winter months reduced variations in relative humidity, so that environmental influences on circulation were minimal and relatively constant. The increase in feet skin temperature was particularly marked in the patient who evidently had the greater impairment of peripheral circulation; in this patient a significant increase in leg skin temperature from oscillation was also noted. In two patients studied during the convalescent phase when peripheral circulation was not clearly impaired, skin temperatures of the legs and feet were not significantly raised by oscillation. These results suggest that an effect of oscillation on lower extremity skin temperature can be more readily demonstrated if the circulation is already impaired when oscillation is begun.

Results of determinations of the effect of oscillation on peripheral blood flow over the area of the whole body were not conclusive. No explanation is available for the differing results of an acute increase in blood flow from oscillation in one patient and a chronic similar effect in another.

\section{Basal metabolism and ventilation}

Tests of basal metabolic rate in normal subjects (1) had shown that oscillation in the Sanders bed did not increase oxygen consumption over that in the resting horizontal position. This finding was confirmed in the present studies on patients with poliomyelitis.

During basal metabolism tests on the normal subjects with the bed oscillating, the metabolism chart indicated periodic shifting of the diaphragm's mid-position synchronous with shifting of the bed from horizontal to foot-down position and return. At this slow rate of rocking one would not expect an increase in resting pulmonary ventilation per minute, and none was noted in either study. However, two poliomyelitis patients with sub-normal vital capacities showed modest increases in this measurement during four to six weeks of oscillation which did not continue after oscillation was stopped, and one of these patients showed a 23 per cent increase in maximum minute ventilation capacity. These suggested influences of oscillation on ventilation led to an interest in the possible effects of rocking at a rapid rate which could be 
synchronized with respiration (25); these latter studies have been reported elsewhere (20).

The present study was not intended to accumulate data which could lead to evaluation of the metabolic effects of rapid rocking, now frequently used in the management of poliomyelitis cases with resniratory involvement, particularly in weaning patients from tank respirators. Rapid rocking was used during part of this study in one patient, and no unusual or significant findings were observed except for increases in vital capacity, tidal air and maximum minute ventilation capacity.

\section{Clinical use of tilt table}

No studies were carried out of the possible clinical usefulness of the tilt table. This has been advocated for the purpose of lessening "the tendency to renal stones" (26) although data supporting the suggestion were not cited. Frequent use of the table might improve vasomotor tone, but the impairment of mechanisms responsible for circulatory control in the upright position seen in the present study suggests that caution should be exercised in the table's use because of the danger of fainting. The possible metabolic derangements and dangers of undue muscle stretching in too early weight-bearing in this disease (27) were mentioned in the preceding report (21).

\section{Clinical application of oscillating bed}

The present generally negative report indicates that the oscillating bed would not be useful for modifying the metabolic derangements of paralytic poliomyelitis. The possibility remains that the bed would have such value in other immobilizing illnesses if applied at their inception. Wyse and Pattee did not employ the oscillating bed in paraplegia until more than one month after paralysis had occurred by which time oscillation was ineffective except for improvement in vasomotor tone.

Beneficial circulatory effects, seen also in both of our studies, suggest the likelihood that the oscillating bed may have more valid use as an aid when ambulation is to be instituted, particularly after several weeks in bed following severe trauma, a cerebro-vascular accident, paraplegia or paralysis due to poliomyelitis. Usefulness of the bed in this respect was recently demonstrated in the rehabili- tation of an associate who had suffered a crippling stroke. Suggestion for this use of the bed came from the observation in healthy subjects that restoration of metabolic and physiological indices to normal came about much more rapidly following immobilization in the oscillating than in the fixed bed (1).

The present study appears to have raised or left unsettled several questions. It seems evident, however, that some means other than the oscillating bed is needed for reduction of calcium loss in paralytic poliomyelitis. One such means will be suggested in the succeeding report.

\section{SUMMARY}

This third paper of a series on studies in paralytic acute anterior poliomyelitis has described the results of a trial of the slowly oscillating bed in eight patients; four patients were placed on the bed during the acute and early convalescent phase, two during the convalescent phase and two during the chronic phase. Patients were oscillated for periods of 17 to 42 days, the daily period of oscillation averaging 17 hours. The principal findings were as follows :

1. Oscillation did not retard the natural increase in calcium excretion occurring during the acute and early convalescent phases. During the convalescent and chronic phases oscillation exerted no reductive action on negative calcium balance. Possible reasons were suggested for the difference in result between this study and one in which oscillation diminished calcium loss in immobilized normal subjects.

2. No certain effect of oscillation was noted on nitrogen excretion and balance, phosphorus, potassium and sodium balance, urinary creatine, creatinine and citric acid or on serum calcium, phosphorus and alkaline phosphatase.

3. In all phases of the disease if the patients were largely confined to bed, they exhibited impairment in the mechanisms essential for adequate circulation in the erect position, as measured by tilt table tests. During the periods on an oscillating bed patients demonstrated definite improvement in these mechanisms, being able to tolerate a longer period of time in the upright tilted position before reaching critically low levels of pulse pressure. 
4. Skin temperature of the feet rose during several weeks on the oscillating bed in two patients with impaired peripheral circulation in the chronic phase of the disease. In two patients in the convalescent phase, oscillation brought about no change in skin temperature.

5. Among other physiological measurements, no definite effect of oscillation was noted on leg girth, muscle strength or basal metabolism.

\section{REFERENCES}

1. Whedon, G. D., Deitrick, J. E., and Shorr, E., Modification of the effects of immobilization upon metabolic and physiologic functions of normal men by the use of an oscillating bed. Am. J. Med., 1949, 6, 684 .

2. Sanders, C. E., Cardiovascular and peripheral vascular diseases. Treatment by a motorized oscillating bed. J. A. M. A., 1936, 106, 916.

3. Barker, N. W., The use of oscillating beds in the treatment of peripheral occlusive arterial disease. Proc. Staff Meet., Mayo Clin., 1939, 14, 618.

4. Wright, I. S., Conservative treatment of occlusive arterial disease. Arch. Surg., 1940, 40, 163.

5. Warshawsky, H., and Dempsey, M. W., The physical therapy of peripheral vascular disease. Arch. Phys. Therapy, 1943, 24, 487.

6. Horton, B. T., Krusen, F. H., and Sheard, C., An evaluation of methods and mechanical devices used in the treatment of peripheral vascular diseases. Arch. Phys. Therapy, 1941, 22, 389.

7. Duryee, A. W., The management of peripheral vascular disease. Bull. New York Acad. Med., 1943, 19, 478.

8. Duryee, A. W., Thrombophlebitis-medical treatment. Bull. New York Acad. Med., 1944, 20, 604.

9. Wyse, D. M., and Pattee, C. J., Effect of the oscillating bed and tilt table on calcium, phosphorus and nitrogen metabolism in paraplegia. Am. J. Med., 1954, 17, 645.

10. Whedon, G. D., and Shorr, E., Metabolic studies in paralytic acute anterior poliomyelitis. I. Alterations in nitrogen and creatine metabolism. J. Clin. Invest., 1957, 36, 942.

11. Deitrick, J. E., Whedon, G. D., and Shorr, E., Effects of immobilization upon various metabolic and phsiologic functions of normal men. Am. J. Med., 1948, 4, 3.
12. Shapiro, S., Sherwin, B., Redish, M., and Campbell, H. A., Prothrombin estimation: a procedure and clinical interpretations. Proc. Soc. Exper. Biol. \& Med., 1942, 50, 85.

13. Hardy, J. D., and Soderstrom, G. F., An improved apparatus for measuring surface and body temperature. Rev. Scient. Instruments, 1937, 8, 419.

14. Stoll, A. M., and Hardy, J. D., Direct experimental comparison of several surface temperature measuring devices. Rev. Scient. Instruments, 1949, 20, 678.

15. Hardy, J. D., and DuBois, E. F., The technic of measuring radiation and convection. J. Nutrition, 1938, 15, 461.

16. Hardy, J. D., and Soderstrom, G. F., Heat loss from the nude body and peripheral blood flow at temperatures of $22^{\circ} \mathrm{C}$ to $35^{\circ} \mathrm{C}$. J. Nutrition, 1938, 16, 493.

17. Stewart, H. J., and Evans, W. F., Peripheral blood flow in myxedema. Arch. Int. Med., 1942, 69, 808.

18. Roth, P., Modifications of apparatus and improved technic adaptable to the Benedict type of respiration apparatus. Boston M. \& S. J., 1922, 186, 457.

19. Graybiel, A., and McFarland, R. A., The use of the tilt-table test in aviation medicine. J. Aviation Med., 1941, 12, 194.

20. Plum, F., and Whedon, G. D., The rapid-rocking bed: its effect on the ventilation of poliomyelitis patients with respiratory paralysis. New England J. Med., 1951, 245, 235.

21. Whedon, G. D., and Shorr, E., Metabolic studies in paralytic acute anterior poliomyelitis. II. Alterations in calcium and phosphorus metabolism. J. Clin. Invest., 1957, 36, 966.

22. Davenport, C. B., and Ekas, M. P., Statistical Methods in Biology, Medicine and Physiology. New York, John Wiley and Sons, 1936, p. 37.

23. Abramson, A. S., Bone disturbances in injuries to the spinal cord and cauda equina (paraplegia); their prevention by ambulation. J. Bone \& Joint Surg., 1948, 30-A, 982.

24. Barker, N. W., and Roth, G. M., The treatment of occlusive arterial disease of the legs by means of the Sanders vasocillator (Sanders bed). Am. Heart J., 1939, 18, 312.

25. Wright, J., The Respir-aid rocking bed in poliomyelitis. Am. J. Nursing, 1947, 47, 454.

26. Stimson, P. M., Poliomyelitis aphorisms. J. Pediat., 1954, 44, 607.

27. Green, W., Importance of rest in the treatment of early convalescent poliomyelitis. Am. J. Dis. Child., 1952, 83, 4. 